\title{
SISTEMA PRODUTIVO DA LARANJA ORGÂNICA E SUAS IMPLICAÇÕES: ESTUDO NO SÍTIO SOS AGROECOLÓGICO, NORDESTE PARAENSE
}

\author{
Amanda Pinheiro Fortaleza'; José Jaime Pessoa do Nascimento Filho²; Marcelo Araújo de Oliveira33; \\ Thiago da Silva Dias"; Marcelo Augusto Machado Vasconcelos ${ }^{5}$; Osvaldo Ryokei Kato ${ }^{6}$. \\ 1Universidade Federal Rural da Amazônia, Belém, Pará, Brasil, amanda.fortaleza1@hotmail.com \\ Universidade Federal Rural da Amazônia, Belém, Pará, Brasil, jaime-linux@hotmail.com \\ 3Universidade Federal Rural da Amazônia, Belém, Pará, Brasil, marcelo.c.de@hotmail.com \\ ^Universidade Federal Rural da Amazônia, Belém, Pará, Brasil, thiagodiasflorestal@gmail.com \\ 5Universidade Federal Rural da Amazônia, Belém, Pará, Brasil, marcelo.augusto@ufra.edu.br \\ ${ }^{6}$ Embrapa Amazônia Oriental, Belém, Pará, Brasil, osvaldokato@gmail.com
}

RESUMO: A produção orgânica no Brasil vem crescendo a cada ano, pois com uma maior demanda por produtos mais saudáveis, vários produtores estão migrando para esse conceito de alimentos. Assim este trabalho tem como objetivo entender a concepção filosófica, bem como fazer uma descrição e analisar as implicações do sistema de produção da laranja orgânica. A pesquisa ocorreu no Sítio SOS Agroecológico, localizado no município de Capitão Poço, Nordeste Paraense. Foi realizada pesquisa exploratória qualitativa junto ao proprietário da área e produtor de laranja orgânica por meio, principalmente, de visitas, entrevistas semiestruturadas, caminhadas transversais na área e registros fotográficos. A produção do sítio é considerada boa, seus principais mercados são feiras orgânicas e grandes supermercados, porém o preço e a logística são os principais entraves, além da certificação, que no Brasil ainda é um processo oneroso. O sistema de produção do Sítio apresenta certa similaridade com a concepção da agricultura biológica e natural, visto que ambos os sistemas visam à redução de custos do produtor rural, a utilização de produtos alternativos e/ou naturais disponíveis na propriedade.

PALAVRAS-CHAVE: Agroecologia, Certificação, Sistemas agroflorestais.

\section{PRODUCTION SYSTEM OF ORGANIC ORANGE AND ITS IMPLICATIONS: STUDY ON THE SITE SOS AGROECOLOGY, NORTHERN PARÁ}

\begin{abstract}
The organic production of produce in Brazil has been increasing very year due higher demand for more health food, and many farmers are migrating to these concepts of food production. Therefore, the aim of this study is to understand the philosophic concept, as well as doing a description and analyzing the implications of the production system of organic orange. The research was done at Sítio SOS Agroecológico, localized in the city of Capitão Poço, northeast of Pará. The qualitative exploratory research was done with the owner of the area, who is also a producer of
\end{abstract}


organic orange, though, mainly, visits, semi structured surveys, transect walks in the area, and photographic records. The production of the site is considered adequate; their main market are organic fairs and big supermarkets; however, price and logistic are the main obstacles, besides the certification, where in Brazil is still an onerous process. The production system of Sitio SOS shows certain similarities with the concept of biologic and natural agriculture since both systems goals are the reduction of the rural producer costs, the use of alternative products and/or natural available on the property.

KEYWORDS: Agroecology, Agroforest systems, Certification.

\section{SISTEMA DE PRODUCCIÓN DE LA NARANJA ORGÁNICA Y SUS IMPLICACIONES: ESTUDIO EN EL SITIO SOS AGROECOLÓGICO, NORDESTE PARAENSE}

RESUMEN: La producción orgánica en Brasil está creciendo cada año como una mayor demanda de productos más saludables, muchos productores están acudiendo a este concepto de alimentos. Por lo que este estudio tiene como objetivo comprender la concepción filosófica, y hacer una descripción y análisis de las implicaciones del sistema de producción orgánico. La investigación se llevó a cabo en Sitio SOS Agroecológico, situada en el condado de Capitão Poço, Nordeste Paraense. Investigación cualitativa exploratoria se llevó a cabo por el propietario de la zona y productor de naranja orgánico a través principalmente de las visitas, entrevistas semiestructuradas, recorridos transversales en la zona y registros fotográficos. La planta de producción se considera bueno, sus principales mercados son los mercados orgánicos y los grandes supermercados, pero el precio y la logística son los principales obstáculos, además de la certificación, que en Brasil todavía es un proceso costoso. El sistema productivo del sitio tiene una cierta similitud con el concepto de la agricultura orgánica y natural, ya que ambos sistemas encaminados a la reducción de los costos de los productores rurales, el uso de productos alternativos y / o naturales disponibles en la propiedad.

PALABRAS CLAVE: Agroecología, Agroforestería, Certificación.

Durante as últimas décadas, a desenvolvimento de novas tecnologias, agricultura vem mudando suas máquinas agrícolas e indústria química, características a partir do que embora impulsione a produção de 
alimentos, também produz efeitos colaterais. A partir da preocupação com tais efeitos colaterais, agricultores desenvolveram métodos e processos agrícolas que segundo eles são seguros e sustentáveis. Trata-se de uma produção baseada na interação dinâmica entre solo, plantas, animais, pessoas, ecossistema e meio-ambiente (IFOAM, 1998).

A crescente preocupação com o meio ambiente tem feito com que o consumidor se torne cada vez mais exigente em relação aos atributos de qualidade e segurança dos produtos e com a preservação do meio ambiente.

A busca irrefutável de aumentos constantes de produtividade agrícola, através do uso de agrotóxicos e adubações minerais pesadas, tem ocasionado a poluição dos alimentos e do meio ambiente em níveis indesejáveis (ASSIS et al., 1995).

Nesse contexto, o processo orgânico de produção vem atuando como uma forma de exploração agrícola ecologicamente adequada frente aos problemas ambientais, abrindo-se espaço para o desenvolvimento da agricultura orgânica, que se apresenta como uma retomada do uso de antigas práticas agrícolas, porém adaptando-as às mais modernas tecnologias de produção agropecuária objetivando assim o aumento da produtividade e causando o mínimo de interferência nos ecossistemas, além de ser uma das alternativas para viabilizar a pequena propriedade (ORMOND et al., 2002).

De acordo com a Lei n¹0.831, de 23 de dezembro de 2003 (BRASIL, 2015a), considera-se:

Sistema orgânico de produção agropecuária todo aquele em que se adotam técnicas específicas, mediante a otimização do uso dos recursos naturais e socioeconômicos disponíveis e o respeito à integridade cultural das comunidades rurais, tendo por objetivo a sustentabilidade econômica e ecológica, a maximização dos benefícios sociais, a minimização da dependência de energia não renovável, empregando, sempre que possivel, métodos culturais, biológicos e mecânicos, em contraposição ao uso de materiais sintéticos, a eliminação do uso de organismos geneticamente modificados e radiações ionizantes, em qualquer fase do processo de produção, processamento, armazenamento, distribuição e comercialização, e a proteção do meio ambiente. 
Para se tornar um agricultor orgânico, é necessário que o candidato seja submetido a um rigoroso processo de investigação das condições ambientais do estabelecimento agrícola e de potencialidade para a produção. As certificadoras devem possuir diretrizes próprias devendo exercer controle apropriado sobre o uso de suas licenças, certificados e marcas de certificação (BRASIL, 2015b).

No Brasil usam-se "Selos de Qualidade" (selo de certificação) juntamente à marca específica de cada produtor para indicar a concordância com as diretrizes, que são atestadas por certificadoras credenciadas junto ao Colegiado Nacional para a Produção Orgânica (CNPOrg) (IBD, 2002).

A cultura e comercialização dos produtos orgânicos no Brasil foram aprovadas pela Lei 10.831, de 23 de dezembro de 2003. Sua regulamentação, no entanto, ocorreu apenas em 27 de dezembro de 2007 com a publicação do Decreto No 6.323 (MAPA, 2015). A demanda por produtos orgânicos no Brasil e no mundo vem aumentando nos últimos anos, mesmo assim, em 2006, apenas 1,75\% dos estabelecimentos eram produtores orgânicos (NUNES, 2006).

Nos últimos dez anos, a produção de citros no Estado do Pará atingiu índices elevados de crescimento, principalmente na microrregião do Guamá, onde se concentram os principais municípios produtores como Capitão Poço, Garrafão do Norte, Irituia e Ourém, constituindo o chamado pólo citrícola do Estado. Com os avanços da citricultura nesse período, o Pará passou a assumir posição de destaque, ficando entre os seis maiores produtores de laranja do Brasil. A área cultivada com citros no Estado do Pará tem crescido rapidamente, atingindo, em 2000, cerca de 14.600 ha, com um rendimento médio de 15,6 toneladas/frutos/ha (LEMOS et al., 2004).

Na microrregião do Guamá, o Sítio SOS Agroecológico tem ganhado destaque. Está localizado no município de Capitão Poço, Nordeste do Estado do Pará, e tem como principal atividade o cultivo da laranja (Citrus sinensis) 
"orgânica". Essa atividade teve início a partir de 1997, mas a comercialização como produto orgânico foi somente a partir de 2007, com a certificação orgânica pelo Instituto Biodinâmico Certificações (IBD).

Dessa forma, o objetivo do presente trabalho é entender a concepção filosófica, bem como fazer uma descrição e analisar as implicações do sistema de produção da laranja orgânica a fim de trazer informações para as instituições de ensino, pesquisa, extensão para nortear os debates e as ações sobre produção orgânica e de conservação ambiental na região Nordeste e demais regiões do Estado do Pará.

A área estudada possui 75 hectares sendo denominada Sítio sos Agroecológico, com posição geográfica S $01^{\circ} 47^{\prime} 57^{\prime \prime}$ W 4706 $40,8^{\prime \prime}$, localizada no município de Capitão Poço (Figura 1).

O município situa-se na zona fisiográfica do Guamá, território do Nordeste Paraense e microrregião do Guamá, com uma área de 2.714,85km. Limita-se ao norte com Ourém, a leste com Santa Luzia do Pará e Garrafão do Norte, ao sul com Ipixuna do Pará e Nova Esperança do Piriá e a oeste com Aurora do Pará, Mãe do Rio e Irituia (NUNES, 2006).

A vegetação do município de Capitão Poço é caracterizada pela cobertura de Floresta Densa Latifolheada de platô, terraços e vegetação aluvial. A área está inserida na condição de frente pioneira, com elevada incidência de desmatamentos e, consequentemente, áreas de capoeira (PORTAL AMAZÔNIA, 2015).

O clima é considerado Ami, de acordo com a classificação de Köppen, tropical quente e úmido, com temperatura média anual de $26,9^{\circ} \mathrm{C}$ e umidade relativa média de $80 \%$ (BASTOS, 1972). A precipitação pluviométrica é de $2.449 \mathrm{~mm}$ anuais, com frequência média de 140 a 180 dias de chuvas, sendo o período mais chuvoso correspondente aos meses de janeiro a abril e o menos chuvoso aos meses de setembro a novembro (SILVA et al., 1999). 
Na área, existe a predominância de solos com horizontes B Latossólicos, caracterizados pelos seguintes tipos: Latossolo Amarelo (textura média), Latossolo Amarelo Cascalhento (textura média), solos Concrecionários Lateríticos, Areias Quartzosas e Latossolos Amarelo (textura argilosa).
Os solos dominantes são os Latossolos Amarelos, de maior ocorrência na Região Amazônica, caracterizados pela baixa fertilidade, textura média e fortemente ácidos (PARÁ, 2006).

Figura 1. Mapa de localização do Sítio SOS Agroecológico, Capitão Poço, Pará, Brasil.

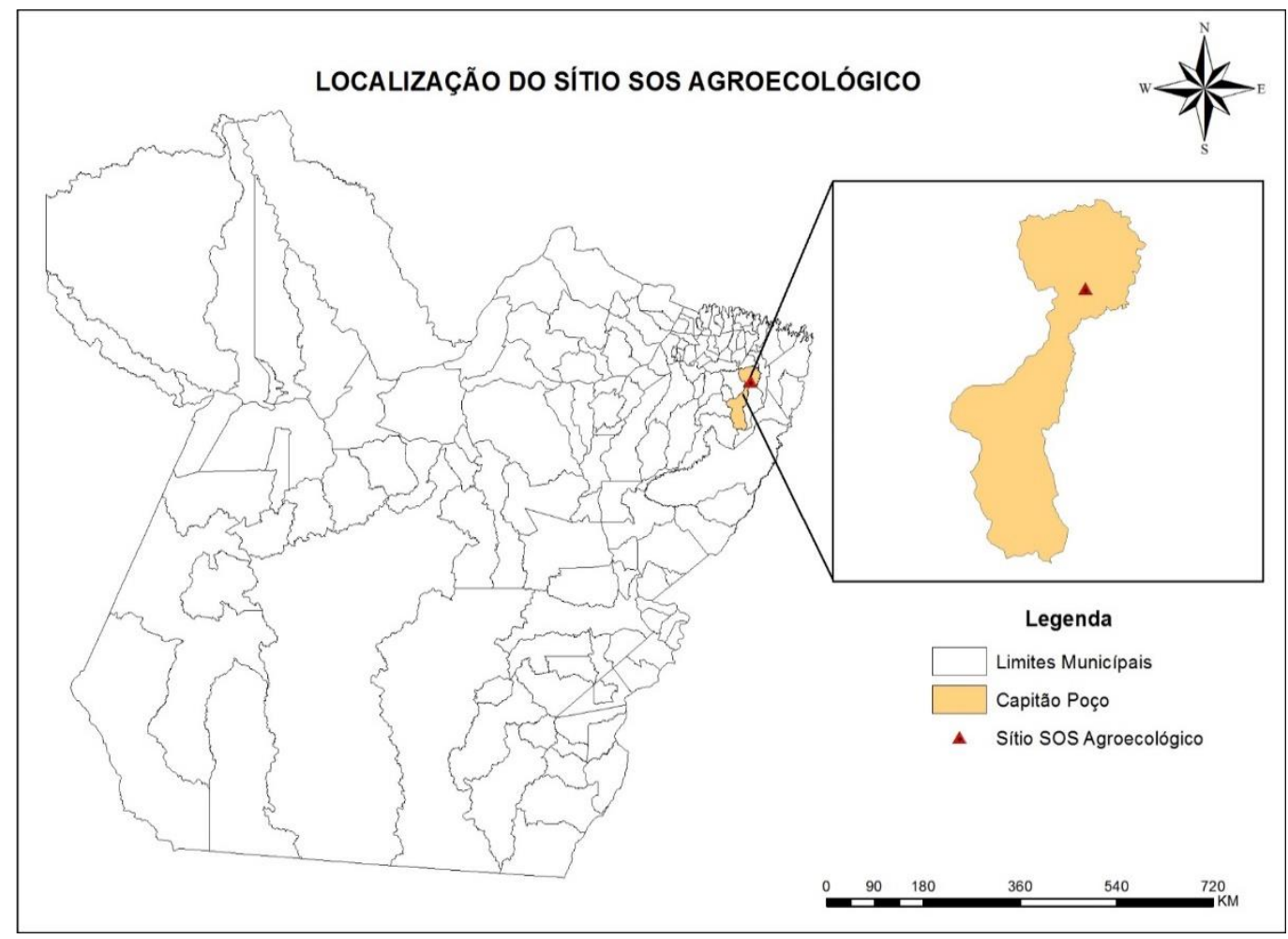

Para o desenvolvimento desse laranja orgânica por meio, estudo, foi realizada uma pesquisa principalmente, de visitas, entrevistas exploratória qualitativa junto ao semiestruturadas, caminhadas proprietário da área e produtor de 
transversais na área e registro fotográfico.

A pesquisa qualitativa possibilita a captação das opiniões e perspectivas dos indivíduos, informações mais difíceis de serem obtidas por uma pesquisa quantitativa. A grande vantagem desse tipo de pesquisa para o estudo das organizações é a riqueza dos detalhes obtidos. Os dados qualitativos expressam descrições minuciosas de situações, acontecimentos sujeitos, experiências, atitudes, crenças e pensamentos (CASSAB, 2007).

A pesquisa de um modo geral, é um procedimento formal, baseado no método de pensamento reflexivo, requerendo um tratamento científico, onde se constitui no caminho para se conhecer a realidade ou para se descobrir verdades. Os dados coletados, obtidos nesse tipo de pesquisa, são colhidos em situações onde os entrevistados na pesquisa transitam e constroem sua vida, onde os modos de vida, as culturas e as experiências eclodem (CASSAB, 2007).
As variáveis observadas e estudadas para o presente trabalho foram: a produção de mudas, principais dificuldades encontradas para a produção orgânica, pragas incidentes, manejo utilizado e a logística de mercado.

De acordo com as entrevistas realizadas junto ao proprietário do Sítio SOS Agroecológico, as mudas são adquiridas pelo sistema convencional, utilizando-se o método de enxertia, que tem como finalidade selecionar as espécies com maior potencial produtivo e diminuir o risco de incidência de pragas e doenças.

Os porta-enxertos atuam em várias características hortícolas e patológicas dos citros, ressaltando: a absorção, síntese e utilização de nutrientes; transpiração e composição química das folhas; resposta aos produtos de abscisão de folhas e de frutos; porte, precocidade de produção e longevidade das plantas; maturação, peso e permanência de frutos na planta; coloração da casca e do suco; teores de açúcares, ácidos e de outros 
componentes do suco; tolerância aos insetos-praga; conservação póscolheita; produtividade e qualidade da fruta (SOUZA et al., 2010).

$\mathrm{O}$ arranjo entre o enxerto e portaenxerto desempenha papel importante na produtividade e qualidade da fruta cítrica. Assim, o sistema produtivo utilizado, as condições climáticas da região, as pragas e doenças existentes e potenciais do mercado a que se destinam as frutas são pontos relevantes a serem considerados (OLIVEIRA et al., 2010).

Para o manejo do plantio, a adubação é realizada através do método de enriquecimento de área, onde ocorre a trituração das plantas "adubadeiras" como a Ingá (Inga edulis Mart) e Mucuna preta (Mucuna aterrima), Puerária (Pueraria phaseoloides (Roxb.) Benth) e plantas mobilizadoras de fósforo: Titonia (Tithonia diversifolia) e Embaúba (Cecropia pachystachya), além da adubação com esterco de carneiro (Ovis aries) no caso dos indivíduos de laranjeira (de 1 a 2 pás por planta). Como o sistema de produção é orgânico, não é utilizado adubos químicos e nem defensivos agrícolas.

Um estudo realizado por Gallo e Rodriguez (1960) apontou a importância das leguminosas e da cobertura morta no aumento da produtividade de laranjeira. Assim, percebe-se que sem o uso de produtos químicos, pode-se obter muitos benefícios na produção de laranja, tanto na produção convencional como na orgânica.

Inicialmente o controle de pragas era realizado com defensivos alternativos na área de estudo do presente trabalho. Mas no momento, o sistema de produção do Sítio SOS Agroecológico se encontra em equilíbrio ambiental. Os efeitos de diferentes coberturas mortas a partir do manejo mecânico com roçadeira lateral que realiza o depósito da fitomassa roçada na linha do pomar conclui que a cobertura morta com vegetação natural apresentou efeito supressivo sobre as plantas daninhas. 
No Sítio SOS Agroecológico são realizados cultivos intercalares nas entre linhas da Laranja, como a Graviola (Annona muricata L.), Caju (Anacardium occidentale L.), Noni (Morinda citrifolia L.), Bacabi (Oenocarpus bacaba Mart.), Abacaxi (Ananas comosus L. Merril.), Mogno brasileiro (Swietenia macrophylla King), Mogno africano (Khaya senegalensis (Desv.) A.Juss.), Castanha do Pará (Bertholletia excelsa Bonpl.), Cedro (Cedrela odorata L.), Andiroba (Carapa guianensis Aubl.), dentre outras que se passaram a compor os Sistemas Agroflorestais (SAFs) com manejo orgânico, onde foram incorporados os princípios agroecológicos de forma a contribuir para conservação da biodiversidade e equilíbrio ambiental da área. Os SAFs implementados na área de produção da Laranjeira contribui para a adubação da cultura, aumentando a produtividade do mesmo através da ciclagem de nutrientes.

As principais ocorrências de pragas e doenças que atacam o plantio são as formigas (Acromyrmex ssp) e a mosca da fruta (Ceratitis anastrepha). A mosca da fruta é considerada a principal praga (Figura 2A), pois a mesma é responsável por transmitir a leprose, denominada Citrus leprosis vírus (CiLV), doença que influência na qualidade visual do fruto (Figura 2B). Para o controle da proliferação da doença, é realizado a poda drástica.

Na produção orgânica deve-se priorizar o uso de variedades resistentes ao controle das principais doenças das fruteiras (BORGES; SOUZA, 2005). A consequência de um plantio misto ou consorciado, diminui a incidência de adubação e o ataque de pragas e doenças, pois se o sistema se encontra em equilíbrio, logo a resistência da cultura é maior.

De acordo com as características das práticas e manejo do sistema produtivo do Sítio SOS Agroecológico percebe-se claramente que o mesmo segue à concepção de dois estilos: a agricultura biológica e agricultura natural. Na primeira destaca-se $\mathrm{O}$ controle biológico e manejo integrado 
de pragas e doenças. Esta agricultura reforça o uso da adubação orgânica e demais técnicas biológicas. Já a segunda, preconiza a menor alteração possível no funcionamento natural dos ecossistemas e utiliza microrganismos benéficos à produção vegetal e animal, conhecidos pela sigla EM (microrganismos eficazes).

Figura 2. A) Mosca da fruta (Ceratitis anastrepha); B) Leprose.

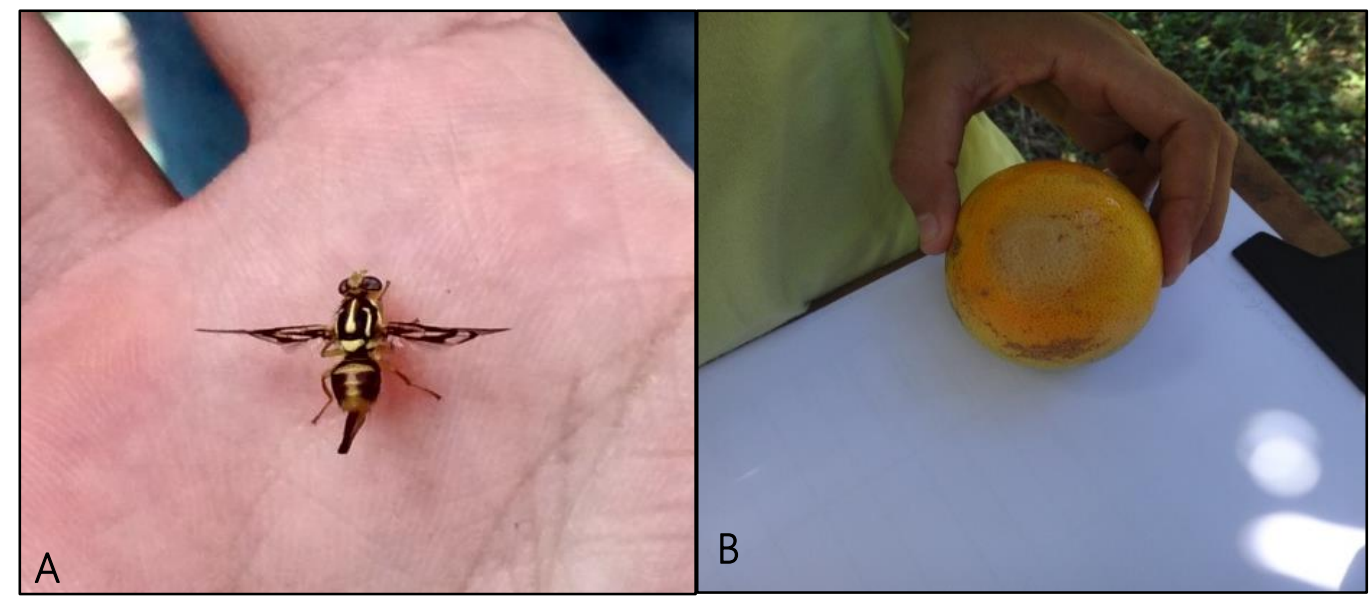

O sistema de funcionamento da

recursos, mantendo-se

boa agricultura biológica tem como produtividade (HODGES, 1981).

princípio fundamental o fato de que a

Quanto à agricultura natural, esta é agricultura tem como base principal as definida como um sistema de ciências biológicas, sendo definido exploração agrícola que se fundamenta como um sistema que tenta manter $\mathrm{o}$ no emprego de práticas que procuram equilíbrio ambiental. A manutenção da tirar o máximo proveito da natureza, ao fertilidade do solo e o controle de que se refere à ecologia e recursos pragas e doenças são feitos pelo uso de processos e ciclos naturais, com um gasto somente moderado de energia e naturais locais. Em outras palavras, as práticas de cultivo de agricultura natural fundamentam-se no método 
natural de formação do solo, contando com a força da natureza e com todos os conhecimentos técnicos científicos adquiridos ao longo da evolução humana (ASSIS, 2005).

Algumas destas formas nãoconvencionais apresentam características estritamente relacionadas à agricultura, enquanto outras ainda acrescentam aspectos relacionados à educação, religião e nutrição. Todavia, dentre as características dos diversos estilos alternativos, as estratégias de produções agrícolas fundadas com base nos conceitos ecológicos visando à reciclagem de nutrientes e de matéria orgânica otimizada, populações de pragas equilibradas e crescente uso múltiplo da terra constituem o ponto em comum entre elas (COSTABEBER, 2007).

Ainda sobre os dois estilos da agricultura biológica e agricultura natural, constatou-se que o custo de produção é considerado baixo, em relação ao convencional, pois não há uso de herbicidas, fungicidas entre outros produtos que aumentam o valor da produção. Segundo Neves et al., (2004) o custo com defensivos na citricultura chega a $45 \%$ do custo de produção.

No quadro abaixo estão algumas das características enfrentadas pelo produtor do Sítio ao qual foi realizado este (Quadro 1).

Vale ressaltar que agricultura orgânica tem como princípios o uso de compostos, plantas de raízes profundas e atuação de micorrizas na saúde dos cultivos. Ultimamente, há grande interesse econômico em torno dessa agricultura que cada vez mais vem sendo encarada como um lucrativo negócio (FEIDEN, 2005). De acordo com as diretrizes do Instituto Biodinâmico Certificações (IBD), as áreas ou unidades que produzam, processem ou exportem produtos orgânicos devem estar claramente separadas de outras que manuseiem produtos convencionais. 
Quadro 1. Aspectos avaliados junto ao produtor de laranja orgânica.

\begin{tabular}{|c|c|}
\hline ASPECTOS AVALIADOS & SÍTIO SOS AGROECOLÓGICO \\
\hline Período de certificação & 1 ano. \\
\hline Espécies florestais & $\begin{array}{l}\text { Mogno nativo e africano, Castanha do Pará, Cedro e } \\
\text { Andiroba. }\end{array}$ \\
\hline Dificuldades na produção de laranja orgânica & $\begin{array}{l}\text { Mão de obra especializada, vizinhos que rodeiam a } \\
\text { propriedade utilizam o sistema convenciona } \\
\text { (Adubação química). }\end{array}$ \\
\hline Custo de produção: Orgânico x Convencional & Menor para o orgânico. \\
\hline Produtividade & Baixa \\
\hline Principais mercados para a comercialização & $\begin{array}{l}\text { Mercado Regional: Feira local e Região } \\
\text { metropolitana; mercado nacional: São Paulo. }\end{array}$ \\
\hline Preço de comercialização & $30 \%$ a mais do que o convencional. \\
\hline
\end{tabular}

No entanto, quando se fala em agricultura biodinâmica, esta possui uma abordagem mais integrada da propriedade rural, procurando vê-la e manejá-la como um organismo vivo. Do ponto de vista prático, o que mais diferencia a agricultura biodinâmica da agricultura orgânica é o uso de determinados preparados incorporados nas pilhas de compostagem e manejos naturais, como o plantio de quebra-ventos, ou mesmo pulverizações realizadas de forma direta sobre as plantas (FEIDEN,
2005). É nesse contexto que o conhecimento quanto às características ecológicas das espécies é de fundamental importância para o sucesso do empreendimento, entre elas se pode citar a floração e frutificação (Figura 3).

Nesse contexto, tem-se utilizado quebra-ventos em SAFs no Sítio SOS Agroecológico como delimitadores naturais. Além do que, a interação entre plantas cítricas e os quebraventos geralmente se concentram em quantificar o efeito do sombreamento 
decorrente dos quebra-ventos instalados sobre o rendimento e a qualidade dos frutos, os danos por vento e por frio e a disseminação de doenças (OLIVEIRA et al., 2010).

Os principais canais de comercialização em ordem decrescente são: feiras, indústria, lojas de produtos orgânicos/naturais e atravessadores. A localização da propriedade e os canais de escoamento de produção estão entre os fatores que mais interferem na dificuldade de comercialização (distante dos grandes centros comerciais e com custo de frete alto, em alguns casos não compensando a venda) (TURRA; GHISI, 2004). O impacto no aumento da produção do produto diminui o valor do frete e abre novas oportunidades de comercialização, tanto a nível regional quanto nacional (Figura 4).

Figura 3. Período de frutificação e floração da laranja orgânica, produzida na área de estudo do Sítio SOS Agroecológico.

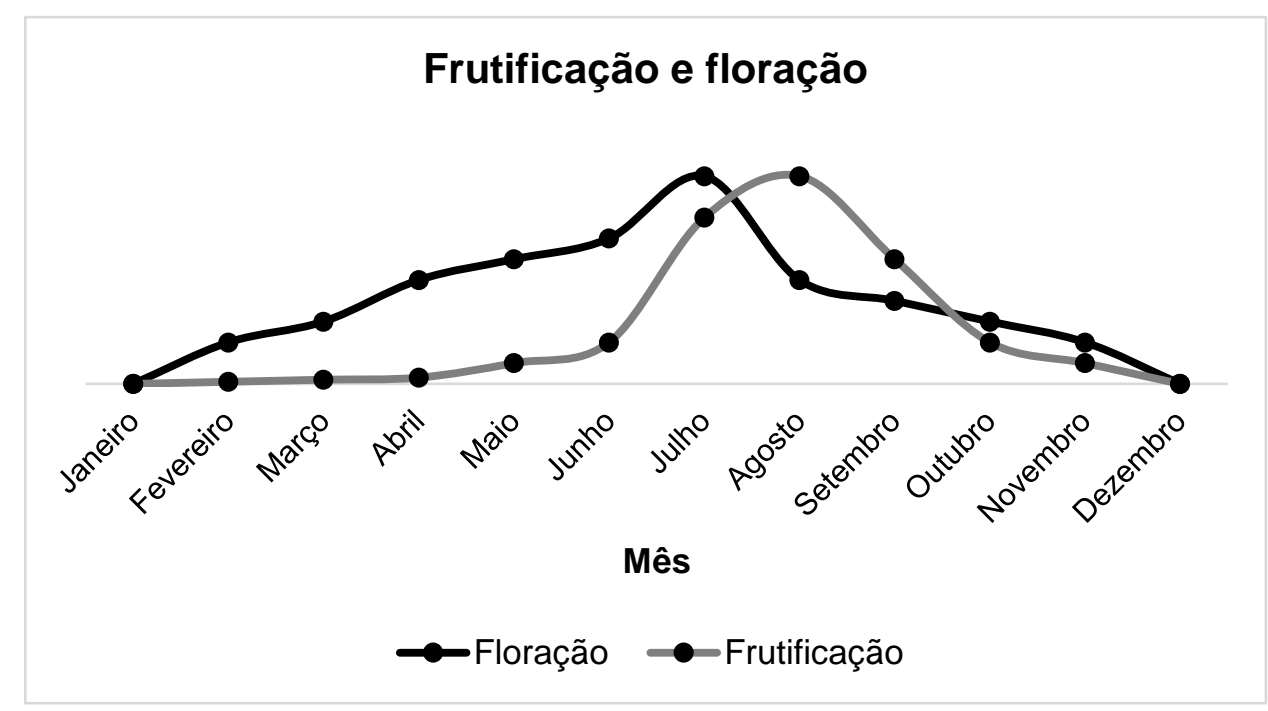


Figura 4. Fluxo da comercialização de laranja orgânica.

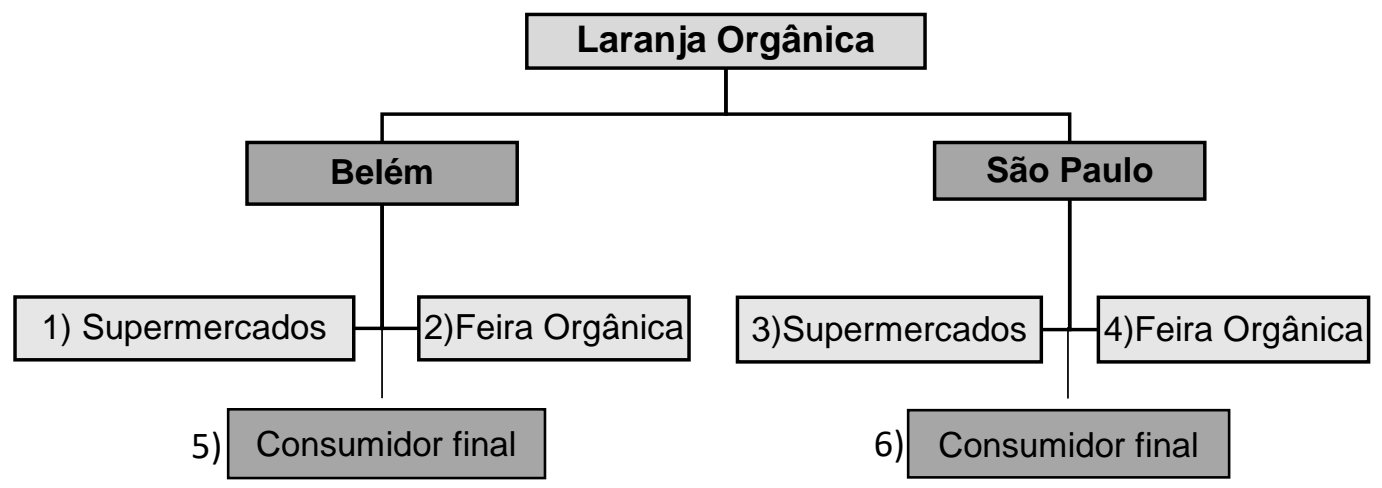

\begin{tabular}{|c|c|}
\hline 1 & $\mathrm{R} \$ 1.200,00 /$ tonelada \\
\hline 2 & $\mathrm{R} \$ 1.200,00 /$ tonelada \\
\hline 3 & $\mathrm{R} \$ 800,00 /$ tonelada \\
\hline 4 & $\mathrm{R} \$ 800,00 /$ tonelada \\
\hline 5 & $\mathrm{R} \$ 2,50 / \mathrm{kg}$ \\
\hline 6 & $\mathrm{R} \$ 4,00 / \mathrm{kg}$ \\
\hline
\end{tabular}

A IBD é responsável pela certificação orgânica do Sítio SOS Agroecológico, onde o mesmo tem validade de um ano. Uma das dificuldades de se obter a certificação orgânica é que o processo é demorado e oneroso, pois a propriedade tem que estar de acordo com as normas exigidas pela legislação vigente e para isto é necessário um tempo maior até que este processo seja alcançado com sucesso.

A principal vantagem do consumo de orgânicos frente aos convencionais refere-se ao menor índice de toxicidade e a manutenção do equilíbrio ambiental. Para o produtor, uma das vantagens desse sistema está relacionada à não utilização dos produtos químicos, já que, de acordo com Lima Neto et al., (2009), um grande número de agricultores não utiliza equipamentos de proteção, sendo estes produtos químicos utilizados de forma indiscriminada.

Além disso, eles se sentem pessoalmente satisfeitos em oferecer aos consumidores produtos de melhor qualidade e ainda promover melhorias 
para a população próxima aos locais de produção

diminuindo

consideravelmente a contaminação

ambiental (PANZENHAGEN et al., 2008). Ainda se pode considerar como

outra vantagem o fato de o cultivo orgânico exigir mais mão-de-obra, gerando empregos ou o aproveitamento da própria mão-deobra familiar.

A produção orgânica possui um custo alto de implantação em decorrência do processo de conversão e certificação que é submetida a propriedade quando da adesão ao cultivo orgânico (BRITTO, 2015). No entanto, com o passar dos anos, os custos de manutenção são inferiores aos da produção tradicional, pois os produtores passam a fabricar muitos dos compostos orgânicos necessários para a atividade, além do preço diferenciado. Este fato é facilmente visualizado nas informações do Sítio estudado (Figura 5).

Figura 5. Percentual anual de despesa e lucro para produção do cultivo orgânico de laranja do Sítio SOS Agroecológico.

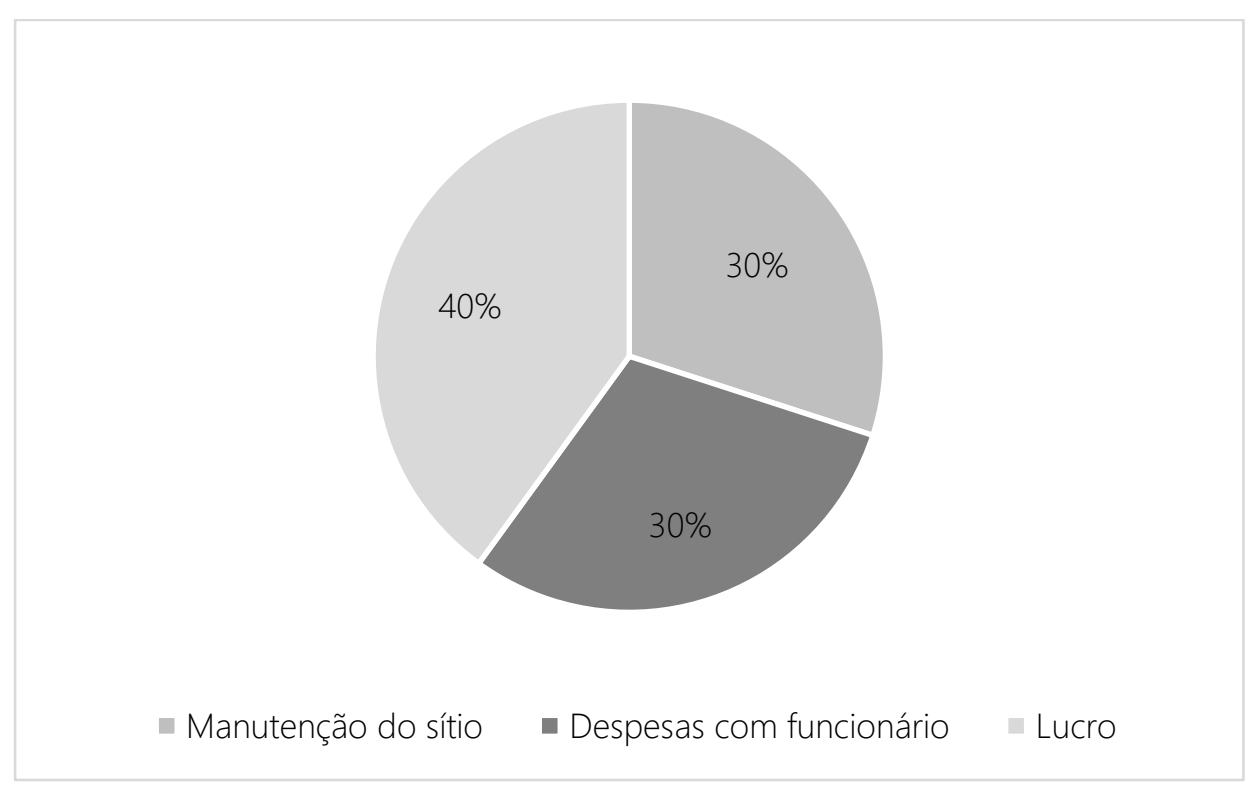


As principais dificuldades do sistema orgânico estão relacionadas a uma mudança nos padrões de produção e consumo, assim como na falta de ações públicas efetivas. Os custos iniciais são elevados, pois fatores como a aquisição de implementos e materiais adequados, sementes, a introdução de práticas de preparo e conservação do solo, assistência técnica entre outros, são inseridos quando se deseja concretizar a conversão da agricultura convencional para orgânica (CAMPANHOLA; VALARINI, 2001).

Outra dificuldade encontrada refere-se ao controle de pragas, já que isso pode acarretar em contaminação do solo, da planta e do homem por vermes, coliformes e excesso de nitrogênio (ABREU JÚNIOR et al., 2005). Como a escala de produção é reduzida devido ao baixo número de agricultores adeptos ao método orgânico, esses produtos tem um maior custo ao consumidor (ALMEIDA JÚNIOR et al., 2008). Porém, um estudo realizado pelo Instituto Gallup revelou que cerca de $70 \%$ dos brasileiros estão dispostos a pagar 30\% a mais por alimentos orgânicos (PORTAL SÃO FRANCISCO, 2015).

Conclui-se que o sistema de produção do Sítio SOS Agroecológico apresenta certa similaridade com a concepção da agricultura biológica e natural, visto que ambos os sistemas visam à redução de custos do produtor rural, a utilização de produtos alternativos e/ou naturais disponíveis na propriedade - tendo como principal produto a Laranja Orgânica - de excelente qualidade e muito apreciada na região.

Também se observa que o manejo sustentável do sistema da Laranja Orgânica do Sítio SOS Agroecológico é caracterizado por um conjunto de práticas conservacionistas e ecológicas que levam o sistema ao equilíbrio com - meio ambiente, o que facilita a certificação e produção escalonada ao mercado consumidor.

Apesar das inúmeras vantagens do sistema orgânico do Sítio sOS Agroecológico de produção, ainda são encontrados obstáculos para a 
permanência da certificação desse novo método na região, uma vez que os produtores têm pouca ou quase nenhuma tradição de produzir organicamente.

\section{REFERÊNCIAS}

ABREU JÚNIOR, C. H.; BOARETTO, A. E.; MURAOKA, T.; KIEHL, J. C. Uso agrícola de resíduos orgânicos potencialmente poluentes: propriedades químicas do solo e produção vegetal. Tópicos Especiais em Ciência do Solo, Viçosa, v.4, p.391470, 2005.

ALMEIDA JÚNIOR, A. R. de; GRAGNANI, J. G.; MAO, J. B.; TEATO, A. C. Publicidade e consumo "responsável": um breve estudo sobre anúncios em revistas brasileiras, 2008. In: IV ENEC (ENCONTRO NACIONAL DE ESTUDOS DO CONSUMO). Rio de Janeiro. Anais... Rio de Janeiro: ENEC, 2008. CD-ROM.

ASSIS, R. L. Agricultura orgânica e agroecológia: questões conceituais e processo de conversão. Embrapa: Seropédica, Rio de Janeiro, 2005. (Documentos, 196).

ASSIS, R. L. de; AREZZO, D. C. de; DEPOLLI, H. Consumo de produtos da agricultura orgânica no Estado do rio de Janeiro. Revista de Administração, São Paulo, v. 30, n. 1, p. 84-89, 1995.
BASTOS, T. X. O estado atual dos conhecimentos das condições climáticas da Amazônia brasileira. In: Instituto de Pesquisa Agropecuária do Norte (Belém, PA). Zoneamento agrícola da Amazônia: 1a aproximação. Belém, PA, 1972, p. 68-122. (IPEAN. Boletim Técnico, 54).

BORGES, A. L.; SOUZA, L. da S. Produção orgânica de frutas. Cruz das Almas: Embrapa Mandioca e Fruticultura Tropical, 2005.

BRASIL. Ministério da Agricultura, Pecuária e Abastecimento. Instrução normativa n. 006 de 10 de janeiro de 2002. Brasília, DF. Disponível em: $<$ www.agrisustentavel.com>. Acesso em: 18 junho 2015 a.

BRASIL. Presidência da República. Lei n¹0.831, de 23 de dezembro de 2003. Dispõe sobre a agricultura orgânica e dá outras providências. Disponível em: $<$ https://www.planalto.gov.br/ccivil_03 /Leis/2003/L10.831.htm>. Acesso em: 18 junho $2015 \mathrm{~b}$.

BRITTO, W. S. F. Análise da viabilidade financeira da agricultura orgânica versus agricultura convencional: o caso da manga no submédio do vale do São Francisco. Disponível em: <http://www.sober.org.br/palestra/12/ 010045.pdf>. Acesso em: 10 novembro 2015.

CAMPANHOLA, C.; VALARINI, P. J. A agricultura orgânica e seu potencial para o pequeno agricultor. Cadernos de Ciência \& Tecnologia, v. 18, n. 3, p. 69-101, set/dez, 2001. 
CASSAB, L. A. Tessitura investigativa: a pesquisa científica no campo humanosocial. Revista Katálysis, Florianópolis, v. 10, n. esp., p. 55-63, 2007.

COSTABEBER, J. A. Transição Agroecológica: do produtivismo a ecologização. In: CAPORAL, F. R.; COSTABEBER, J. A. Agroecologia e Extensão Rural. Contribuições para a promoção do desenvolvimento sustentável. Brasília: MDA/SAF/DATER - 2007. p. 18-48.

FEIDEN, A. Agroecologia: introdução e conceitos. In: AQUINO, A. M. de; ASSIS, R. L. de. Agroecologia: princípios e técnicas para uma agricultura orgânica sustentável. Brasília: Embrapa Informação Tecnológica, 2005. p. 4969.

GALLO, J. R.; RODRIGUEZ, O. Efeitos de algumas práticas de cultivo do solo na nutrição mineral dos citros. Bragantina, v. 19, p. 345-360, 1960.

HODGES, R. D. An Agriculture for the future. In: STONEHOUSE, B. (Ed.). Biological husbandry; a scientific approach to organic farming. London: Butterworths, p. 1-14, 1981.

IFOAM. General assembly em Mar del Plata. Argentina, nov. 1998.

IBD (INSTITUTO BIODINÂMICO). Diretrizes para o padrão de qualidade orgânico Instituto Biodinâmico. 11 ed. Botucatu, 2002. Disponível em: <http://www.ibd.com.br>. Acesso em: 19 junho 2015.
LEMOS, W. de P.; VelOSO, C. A. C.; RIBEIRO, S. I. Identificação e controle das principais pragas em pomares de citros no Pará. Embrapa Amazônia Oriental (Comunicado Técnico). $1^{a}$ ed. Belém, PA, 2004.

LIMA NETO, J. de A.; RIBEIRO, M. R.; CORREAA, M. M.; SOUZA JÚNIOR, V. S. de; LIMA, J. F. W. F.; FERREIRA, R. F. de A. e L. Caracterização e gênese do caráter coeso em Latossolos Amarelos e Argissolos dos Tabuleiros Costeiros do Estado de Alagoas. Revista Brasileira de Ciência do Solo, v. 33, p. 1001-1011, 2009.

MAPA (MINISTÉRIO DA AGRICULTURA). Desenvolvimento Sustentável. Orgânicos. Legislação. Disponível em: $<$ www.agricultura.gov.br>. Acesso em: 18 junho 2015.

NEVES, M. F.; LOPES, F. F.; ROSSI, R. M.; MELO, P. A. de O. Metodologias de análise de cadeias agroindustriais: aplicação para citros. Revista Brasileira de Fruticultura, Jaboticabal-SP, v. 26, n. 3, p. 468-473, 2004.

NUNES, E. P. (Presidente). Censo Agropecuário 2006: Brasil, grandes regiões e unidades de federação. Ministério do Planejamento, Orçamento e Gestão. Instituto Brasileiro de Geografia e Estatística (IBGE). Rio de Janeiro, 2006. 177p.

OLIVEIRA, R. P. de; SCIVITTARO, W. B.; SCHRODER, E. C.; ESSWEIN, F. J. Produção orgânica de citros no Rio Grande do Sul. Pelotas/RS: Embrapa 
Clima Temperado (Sistema de Produção 20), 2010. 296p.

ORMOND, J. G. P.; PAULA, S. R. L. da; FAVERET FILHO, P.; ROCHA, L. T. M. da. Agricultura orgânica: quando o passado é futuro. BNDES Setorial, Biblioteca Digital, Rio de Janeiro, n. 15, p. 3-34, 2002.

PANZENHAGEN, N. V.; KOLLER, O. C.; VAQUIL, P. D.; SOUZA, P. V. D. de; SOGLIO, F. K. D. Aspectos técnicoambientais da produção orgânica na região citrícola do Vale do Rio Caí, RS. Ciência Rural, Santa Maria, v. 38, n. 1, p. 90-95, 2008.

PARÁ. Secretaria Executiva de Estado de Planejamento, Orçamento e Finanças. Estatística Municipal de Capitão Poço. Belém: SEPOF, 2006. 47p.

PORTAL AMAZONIA DE A a Z. Capitão-Poço: Aspectos históricos e culturais. Disponível em: $<$ portalamazonia.globo.com >. Acesso em: 20 junho 2015.

PORTAL SÃO FRANCISCO. Alimentos orgânicos e convencionais. Disponível em:

<http://www.portalsaofrancisco.com.b r>. Acesso em: 10 novembro 2015.

SAN MARTIN MATHEIS, H. A. Efeitos de diferentes coberturas mortas obtidas a partir do manejo mecânico com roçadeira lateral na dinâmica populacional de plantas daninhas em citros. ESALQ-USP, Piracicaba, 2004. 68p.
SILVA, B. N. R. da; SILVA, L. G. T.; ROCHA, A. M. A.; SAMPAIO, S. M. N. Interação biofísica e do uso da terra na dinâmica da paisagem do município de Capitão Poço - $\mathrm{Pa}$, em sistema de informação geográfica. Embrapa Amazônia Oriental. Belém, Documentos, n. 10, 1999, 42p.

TURRA, C.; F. GHISI. Produção de laranja orgânica no Brasil: produção, mercado e tendências, 2004. In: XLII CONGRESSO DA SOCIEDADE BRASILEIRA DE ECONOMIA E SOCIOLOGIA RURAL, 32, Fortaleza. Anais... Fortaleza: CONGRESSO DA SOCIEDADE BRASILEIRA DE ECONOMIA E SOCIOLOGIA RURAL, 2004. 